\title{
Benefits of ultra-fast-track anesthesia for children with congenital heart disease undergoing cardiac surgery
}

\author{
Jing $\mathrm{Xu}^{\dagger}$, Guanghua Zhou ${ }^{\dagger}$, Yanpei Li ${ }^{*}$ and $\mathrm{Na} \mathrm{Li}{ }^{*}$
}

\begin{abstract}
Background: To compare the outcomes of ultra-fast-track anesthesia (UFTA) and conventional anesthesia in cardiac surgery for children with congenital heart disease (CHD) and low birth weight.

Methods: One hundred and ninety-four CHD children, aged 6 months to 2 years, weighting 5 to $10 \mathrm{~kg}$, were selected for this study. The 94 boys and 100 girls with the American Society of Anesthesiologists (ASA) physical status III and IV were randomly divided into two groups each consisting of 97 patients, and were subjected to ultra-fast-track and conventional anesthesia for cardiac surgery. For children in UFTA group, sevoflurane was stopped when cardiopulmonary bypass (CPB) started and cis-atracurium was stopped at the beginning of rewarming, and remifentanil $(0.3 \mu \mathrm{g} / \mathrm{kg} / \mathrm{mim})$ was then infused. Propofol and remifentanil were discontinued at skin closure. 10 min after surgery, extubation was performed in operating room. For children in conventional anesthesia group, anesthesia was given routinely and they were directly sent to ICU with a tracheal tube. Extubation time, ICU stay and hospital stay after operation were recorded. Sedationagitation scores (SAS) were assessed and adverse reactions as well as other anesthesia -related events were recorded.

Results: The extubation time, ICU stay and hospital stay were significantly shorter in UFTA group $(P<0.05)$ and SAS at extubation was lower in UFTA group than in conventional anesthesia group, but similar in other time points. For both groups, no airway obstruction and other serious complications occurred, and incidence of other anesthesia -related events were low.
\end{abstract}

Conclusions: UFTA shortens extubation time, ICU stay and hospital stay for children with CHD and does not increase SAS and incidence of adverse reactions.

Keywords: Ultra-fast anesthesia, Congenital heart disease, Low weight children, Extubation time

\section{Background}

Fast-track anesthesia (FTA) is a procedure that enables extubation in intensive care unit (ICU) within $6 \mathrm{~h}$ after surgery to facilitate the recovery of consciousness and autonomous breathing. It has been safely applied to cardiac surgery since the 1990 s $[1,2]$. FTA is feasible and safe and reduces the occurrence of ventilatorinduced complications, thereby decreasing ICU stay, resource use and cost [3-5]. Ultra-fast tract anesthesia (UFTA) was developed after fast-track anesthesia to further optimize the use of medical resource. With UFTA,

\footnotetext{
*Correspondence: yanpei508@163.com; lina13120@163.com

${ }^{+}$Jing Xu and Guanghua Zhou contributed equally to this work.

Department of Anesthesiology, China Emergency General Hospital, 29

Liufangnanli Rd, Beijing 100028, China
}

extubation is performed immediately or within $1 \mathrm{~h}$ after surgery in the operating room [6]. The benefits of UFTA include lower incidence of postoperative complications, better hemodynamic performance, shorter ICU stay [7-9].

Congenital heart disease (CHD) is the most common type of congenital anomaly, occurring in up to $1 \%$ of all live births. Children with CHD often have abnormalities in brain maturation and brain injury $[10,11]$. Surgery is one of the most common options for treatment $[12,13]$. Anesthesia procedures are ideal for medical and cardiac surgical management. The risks of the procedures include cardiovascular and respiratory complications from anesthesia and sedation and a potentially underappreciated risk of neurocognitive dysfunction [14] and improvement in anesthesia management would

(c) The Author(s). 2019 Open Access This article is distributed under the terms of the Creative Commons Attribution 4.0 International License (http://creativecommons.org/licenses/by/4.0/), which permits unrestricted use, distribution, and 
reduce the risk. In this study, we aimed to investigate the outcomes of UFTA in CHD children in cardiac surgery and to assess the effect of UFTA in reducing postoperative complication.

\section{Methods}

\section{Subjects}

This was a prospective study. CHD children, aged 6 months to 2 years and admitted to our hospital, were selected for this study. They weighted 5 to $10 \mathrm{~kg}$ with the American Society of Anesthesiologists (ASA) physical status III and IV. Children were excluded if they had respiratory tract infection within 2 weeks of surgery and organ complications. Children were also excluded if they could not interrupt ventilation during cardiopulmonary bypass $(\mathrm{CPB})$ and had severe pulmonary hypertension before operation. The study protocols were approved by Ethics Committee of China Emergency General Hospital and informed consent was obtained from every guardian of child participated in the study.

\section{Grouping and treatment}

The patients (94 boys and 100 girls) were randomly divided into two groups each consisting of 97 patients, and were subjected to UFTA and conventional anesthesia before surgeries. The surgeries were performed by the same team of surgeons, anesthesiologists, and postoperative physicians. For children in UFTA group, cisatracurium was stopped and remifentanil $(0.3 \mu \mathrm{g} / \mathrm{kg} / \mathrm{min})$ was infused at rewarming. At the onset of skin closure, propofol and remifentanil were discontinued. During operation, the patients were continuously infused with dexmedetomidine $(1 \mu \mathrm{g} / \mathrm{kg} / \mathrm{h})$ till they were moved to ICU. After operation, $0.375 \%$ ropivacaine was used to block the peripheral nerves. Patients were switched to spontaneous ventilation after a trial of spontaneous ventilation using synchronous intermittent mandatory ventilation (SIMV). Extubation was performed within 10 min after surgery in the operating room and the patients were sent to ICU with facemask to supply oxygen (target SpO2 94-100\%). Children in conventional anesthesia group were supplemented with midazolam $(0.05 \mathrm{mg} / \mathrm{kg})$ and sufentanil $(1 \mu \mathrm{g} / \mathrm{kg})$ at rewarming after CPB. After surgery, the anesthetics were stopped and the patients were sent to ICU with a tracheal tube. They were extubated once all signs were normal as reported [15].

\section{Anesthesia method and hemodynamic monitoring}

No preoperative medication was used in all children. ECG, HR, RR and $\mathrm{SPO}_{2}$ were monitored in the operating room. Anesthesia was induced using ketamine $(1-2 \mathrm{mg} /$ $\mathrm{kg})$, atropine $(0.01 \mathrm{mg} / \mathrm{kg})$, midazolam $(0.05-0.10 \mathrm{mg} / \mathrm{kg})$, cis-atracurium $(0.1-0.2 \mathrm{mg} / \mathrm{kg})$ and sufentanil $(0.5-1.0 \mu \mathrm{g} /$ $\mathrm{kg})$. Mechanical ventilation was given via orotracheal intubation. Tidal volume (VT) was set at $10 \mathrm{ml} / \mathrm{kg}$, Fraction of inspiration $\mathrm{O}_{2}\left(\mathrm{FiO}_{2}\right)$ at $40-50 \%$, respiratoryexchange ratio (RR) at 22-24 time/min, inspiration (I): expiration (E) at 1:2, end-tidal partial pressure of carbon dioxide $\left(\mathrm{PETCO}_{2}\right)$ at $35-40 \mathrm{mmHg}$. After the induction, blood pressure (BP) was monitored via a radial artery catheter and central venous pressure (CVP) was monitored via catheter placed in right internal jugular vein. Anesthesia was maintained through the inhalation of $1-2 \%$ sevoflurane, and the patients were infused with propofol $(3 \mathrm{mg} / \mathrm{kg} / \mathrm{h})$, cis-atracurium $\quad(0.1 \mathrm{mg} / \mathrm{kg} / \mathrm{h})$ and dexmedetomidine $(1 \mu \mathrm{g} / \mathrm{kg} / \mathrm{h})$ throughout the surgery. The concentration of sevoflurane was adjusted based on hemodynamics. Additional midazolam (0.05 $\mathrm{mg} / \mathrm{kg})$ and sufentanil $(1 \mu \mathrm{g} / \mathrm{kg})$ were given before skin incision. Sevoflurane was discontinued when CPB started.

Postoperative pain was assessed using visual analogue scale (VAS) as reported [16], and morphine $(10 \mu \mathrm{g} / \mathrm{kg} / \mathrm{h})$ was infused if VAS was $>4$ and stopped if VAS was $<2$. The Riker Sedation-Agitation Scale (SAS) was used to assess the sedation-agitation status after surgery [17], and dexmedetomidine $(0.2 \mu \mathrm{g} / \mathrm{kg} / \mathrm{h})$ was infused if SAS was $>5$.

\section{Assessment}

MAP, HR and CVP were recorded before anesthesia induction $\left(\mathrm{T}_{0}\right)$, after intubation $\left(\mathrm{T}_{1}\right)$, at incision $\left(\mathrm{T}_{2}\right)$, before and during $\mathrm{CPB}\left(\mathrm{T}_{3}\right.$ and $\left.\mathrm{T}_{4}\right)$, before and after extubation $\left(\mathrm{T}_{5}\right.$ and $\mathrm{T}_{6}$ ). Extubation time (the interval between the end of operation and extubation), ICU stay and postoperative hospitalization stay were also recorded. SAS at extubation, and 6,12 and $24 \mathrm{~h}$ after operation were assessed. Adverse reactions (airway obstruction) as well as other relevant events after operation were recorded.

\section{Statistical analysis}

The data were analysed by SPSS version 20.0 for Windows (SPSS Inc., Chicago, IL, USA). The normality of distribution of continuous variables was tested by onesample Kolmogorov-Smirnov test. Continuous variables with normal distribution were presented as mean \pm s.d. (standard derivation); non-normal variables were reported as median (interquartile range [IQR]). Means of 2 continuous normally distributed variables were compared by independent samples Student's t test. The frequencies of categorical variables were compared using Pearson $X^{2}$ or Fisher's exact test, when appropriate. A value of $P<0.05$ was considered significant.

\section{Results}

A total of 194 children were enrolled in this study, 97 in each group. Two groups of patients had no difference in gender, age, body weight, CHA classification, ASA grade, surgical methods, anesthesia time, CPB time and block time (Table 1). 
Table 1 Baseline comparison of children underwent ultra-fast track anesthesia and conventional anesthesia

\begin{tabular}{|c|c|c|c|}
\hline Parameters & Ultra-fast track anesthesia $(n=97)$ & Conventional anesthesia $(n=97)$ & $P$ value \\
\hline Male/female (no.) & $45 / 52$ & $49 / 48$ & 0.231 \\
\hline Age (year) & $1.2 \pm 0.5$ & $1.1 \pm 0.5$ & 0.331 \\
\hline Body weight (kg) & $9.1 \pm 1.1$ & $9.2 \pm 1.1$ & 0.289 \\
\hline No. pre-term patients & 46 & 44 & 0.782 \\
\hline Birth weight (kg) & $2.3 \pm 0.46$ & $2.2 \pm 0.38$ & 0.389 \\
\hline ASAIII NI (no.) & $52 / 45$ & $46 / 51$ & 0.254 \\
\hline \multicolumn{4}{|l|}{ CHD classification } \\
\hline Atrial septal defect (no.) & 48 & 52 & 0.612 \\
\hline Ventricular septal defect (no.) & 30 & 30 & 0.452 \\
\hline Atrioventricular septal defect & 2 & 3 & 0.652 \\
\hline D-transposition of the great arteries & 4 & 3 & 0.978 \\
\hline Tetralogy of fallot (no.) & 19 & 15 & 0.334 \\
\hline Coarctation of the aorta & 2 & 3 & 0.778 \\
\hline Interruption arterial arch & 1 & 1 & 0.978 \\
\hline Pulmonary stenosis & 5 & 4 & 0.878 \\
\hline Ventricular outflow tract obstruction & 6 & 8 & 0.478 \\
\hline Anesthesia time (h) & $3.4 \pm 1.1$ & $3.3 \pm 1.0$ & 0.342 \\
\hline Surgery time (min) & $297.1 \pm 22.8$ & $289.0 \pm 20.5$ & 0.551 \\
\hline CPB time (min) & $47.4 \pm 11.8$ & $46.3 \pm 10.7$ & 0.234 \\
\hline Block time (min) & $30.2 \pm 8.9$ & $31.4 \pm 9.1$ & 0.331 \\
\hline
\end{tabular}

Furthermore, no difference in MAP, HR and CVP was observed between the two groups at different time points (Table 2). However, extubation time, ICU stay and hospital stay were significantly shorter in the UFTA group than in conventional group $(P<0.05$, Table 3$)$.

The SAS score of UFTA group was significantly lower than that of traditional anesthesia group at extubation $(P<0.05)$, but the scores were similar 6,12 and $24 \mathrm{~h}$ after operation (Table 3). Other anesthesia-related parameters such as the incidence of continuous positive airway pressure (CPAP) use and reintubation rate were similar between the two groups, but the number of patients with ventilator-associated pneumonia was less in UFTA group than in conventional group $(P<0.05$, Table 4), although the numbers were small in both groups. The incidence of adverse events were low and similar in both group and no airway obstruction was not observed in either group (Table 5).

\section{Discussion}

Our results show that the extubation time is significantly shorter in the UFTA group than in conventional group. Furthermore, the ICU stay and hospitalization stay are also shorter. No serious hemodynamic changes, nor serious complications are observed in neither groups, confirming that UFTA is safe for anesthesia management in CHD operation.

UFTA was developed to optimize perioperative anesthesia operations and management to shorten intubation time after operation for fast recovery of patients. A Meta-analysis of randomized controlled trials with large sample size showed that compared with conventional

Table 2 Comparison of MAP, HR and CVP between children undergoing ultra-fast track anesthesia and conventional anesthesia

\begin{tabular}{|c|c|c|c|c|c|c|c|c|c|}
\hline Parameters & Anesthesia & No. case & $\mathrm{T}_{0}$ & $\mathrm{~T}_{1}$ & $\mathrm{~T}_{2}$ & $\mathrm{~T}_{3}$ & $\mathrm{~T}_{4}$ & $T_{5}$ & $\mathrm{~T}_{6}$ \\
\hline MAP & UTFA & 97 & $60.9 \pm 5.6$ & $56.9 \pm 4.2$ & $56.6 \pm 4.1$ & $50.2 \pm 5.4$ & $30.1 \pm 2.2$ & $59.4 \pm 3.9$ & $59.1 \pm 3.6$ \\
\hline$(\mathrm{mmHg})$ & Conventional & 97 & $60.5 \pm 5.3$ & $57.3 \pm 4.0$ & $56.4 \pm 4.5$ & $49.6 \pm 4.8$ & $29.5 \pm 2.4$ & $61.4 \pm 4.2$ & $60.2 \pm 4.8$ \\
\hline$H R$ & UTFA & 97 & $130.4 \pm 4.3$ & $129.3 \pm 4.3$ & $124.4 \pm 4.9$ & $128.4 \pm 4.3$ & / & $136.4 \pm 4.6$ & $136.4 \pm 6.3$ \\
\hline (time/m) & Conventional & 97 & $129.4 \pm 4.1$ & $130.4 \pm 4.1$ & $131.4 \pm 4.3$ & $131.4 \pm 4.3$ & / & $137.2 \pm 4.8$ & $136.8 \pm 5.8$ \\
\hline CVP & UTFA & 97 & $4.5 \pm 0.9$ & $4.9 \pm 0.7$ & $5.3 \pm 1.0$ & $5.3 \pm 1.1$ & / & $6.4 \pm 0.3$ & $6.4 \pm 0.4$ \\
\hline$(\mathrm{mmHg})$ & Conventional & 97 & $4.6 \pm 0.8$ & $5.0 \pm 0.9$ & $5.2 \pm 1.2$ & $5.2 \pm 1.0$ & / & $6.8 \pm 0.5$ & $6.8 \pm 0.4$ \\
\hline
\end{tabular}


Table 3 Comparison of extubation time, ICU stay, postoperative hospital stay and SAS scores between children undergoing ultra-fast track anesthesia and conventional anesthesia

\begin{tabular}{lll}
\hline & $\begin{array}{l}\text { Ultra-fast track } \\
\text { anesthesia }\end{array}$ & $\begin{array}{l}\text { Conventional } \\
\text { anesthesia }\end{array}$ \\
\hline No. case & 97 & 97 \\
Extubation time (min) & $22.9 \pm 3.5^{\mathrm{a}}$ & $189.1 \pm 31.2$ \\
ICU stay (h) & $20.7 \pm 6.5^{\mathrm{a}}$ & $28.5 \pm 4.2$ \\
Postoperative hospital stay (d) & $11.5 \pm 3.0^{\mathrm{a}}$ & $16.1 \pm 2.4$ \\
SAS scores & & \\
$\quad$ At extubation & $3.8 \pm 0.6^{\mathrm{a}}$ & $4.8 \pm 0.7$ \\
6 h- postoperation & $3.9 \pm 0.4$ & $3.9 \pm 0.6$ \\
12 h- postoperation & $4.0 \pm 0.6$ & $4.0 \pm 0.6$ \\
24 h- postoperation & $4.0 \pm 0.5$ & $3.9 \pm 0.5$ \\
\hline a $<0.05$ vs conventional anesthesia & &
\end{tabular}

anesthesia management, UFTA is relatively low-risk and safe in terms of fatality and mortality with shorter extubation time and ICU stay [18].

Prolonged tracheal intubation and mechanical ventilation are major risk factors for respiratory-related complications [19]. A large number of studies have shown that compared with conventional anesthesia management for cardiac surgery, extubation in the operating room after surgery reduces the use of muscle relaxants, facilitates the restoration of spontaneous breathing, decreases the risks of ventilator-related iatrogenic lung inflammation, respiratory tract damage and other pulmonary complications [20]. A propensity score matching analysis showed that the use of UFTA in patients with low to moderate risks of cardiac surgery would improve cost-effectiveness and outcomes as compared to conventional anesthesia management [21]. A prospective observational study showed that extubation in the operating room was successful in $87.1 \%$ of the patients without any increase in mortality and morbidity, but with a decrease in ICU length of stay and less use of hospital resources [22].

Table 4 Comparison of ventilator-associated pneumonia and continuous positive airway pressure use and reintubation rate between children undergoing ultra-fast track anesthesia and conventional anesthesia

\begin{tabular}{lll}
\hline & $\begin{array}{l}\text { Ultra-fast track } \\
\text { anesthesia }\end{array}$ & $\begin{array}{l}\text { Conventional } \\
\text { anesthesia }\end{array}$ \\
\hline No. case & 97 & 97 \\
Ventilator-associated pneumonia $(\mathrm{n})$ & 3 & $5^{\text {a }}$ \\
$\begin{array}{l}\text { Continuous positive airway pressure } \\
\text { use }(\mathrm{n})\end{array}$ & 3 & 3 \\
Reintubation (n) & 5 & 6 \\
Respiratory tract infections (n) & 3 & 4 \\
\hline
\end{tabular}

${ }^{\mathrm{a}} P<0.05$ vs conventional anesthesia
Table 5 Comparison of adverse events between children undergoing ultra-fast track anesthesia and conventional anesthesia

\begin{tabular}{lll}
\hline Adverse event & Ultra-fast track anesthesia & Conventional anesthesia \\
\hline No. case & 97 & 97 \\
Airway obstruction & 0 & 0 \\
Arrhythmia & 1 & 1 \\
Infection & 1 & 2 \\
Bleeding & 1 & 1 \\
Pneumothorax & 0 & 0 \\
\hline
\end{tabular}

${ }^{\mathrm{a}} P<0.05$ vs conventional anesthesia

For CHD surgery, the optimization in UFTA mainly includes perioperative anesthesia managements, such as anesthesia method, selection of anaesthetics, control of perioperative body temperature and postoperative analgesia. In the present study, all children were given a combined intravenous-inhalational anesthesia with sufentanil before CPB. The anesthetic depth was adjusted based on the circulation to reduce the stress induced by extubation and thoracotomy. Remifentanil and propofol infused through the veins after postoperative rewarming in the UFTA group, which was used to provide sedative and analgesic effect and minimize surgical stimulation-induced stress and intraoperative awareness, are ultra-short-acting. They also reduce the dose of sufentanil during operation for better early extubation and postoperative respiratory depression and duration of ventilation time. Studies have also shown that reducing the use of narcotics and analgesics help the recovery of pulmonary function and gastrointestinal function [21].

Perioperative body temperature is a major factor affecting extraction after cardiac surgery [23]. In the present study, body temperature was kept above $36.0^{\circ} \mathrm{C}$. This would accelerate the metabolism of anesthetics and muscle relaxants for better homeostasis of internal environment. Postoperative analgesia can affect extubation and prognosis after cardiac surgery. We used ropivacaine and dexmedetomidine combined with morphine for analgesia in UTFA group. The outcomes are satisfactory and no adverse events such as post-operative agitation were observed. This is important for better and early recovery of pulmonary function.

There are also limitations in this study. For example, hematological parameters related to ventilator-associated pneumonia, such as procalcitonin was not measured; the size of sample was relatively small and most of the patients had mild illness without severe pulmonary artery hypertension before operation. Therefore, studies with larger sample size and more complicated CHD surgeries are needed to further validate the feasibility of UFTA in CHD children. 


\section{Conclusions}

UFTA generates stable hemodynamics during operation, shorter extubation time, shorter ICU and hospitalization stay without increase in adverse reactions. It is worthy of recommendation for clinical practice.

\section{Abbreviations \\ ASA: American Society of Anesthesiologists; BP: Blood pressure; CHD: Congenital heart disease; CPB: Cardiopulmonary bypass; CVP: Central venous pressure; E: Expiration; ICU: Intensive care unit; $\mathrm{PETCO}_{2}$ : Partial pressure of carbon dioxide; RR: Respiratory-exchange ratio; SAS: Sedation- agitation scores; SIMV: Synchronous intermittent mandatory ventilation;} UFTA: Ultra-fast-track anesthesia; VAS: Visual analogue scale; VT: Tidal volume

\section{Acknowledgements}

Not applicable.

\section{Authors' contributions}

JX, GZ, and NL: Project conceptualization, investigation and data analysis. GZ, YL and NL: Data collection, analysis and methodology development. JX, GZ, $Y L$ and NL manuscript writing. The manuscript was read and approved by all authors.

\section{Funding}

none.

\section{Availability of data and materials}

The datasets used and/or analysed during the current study are available from the corresponding author on reasonable request.

\section{Ethics approval and consent to participate}

The study was approved by the Research Ethics Committee of China Emergency General Hospital and informed consent was obtained from every guardian of child participated in the study.

\section{Consent for publication}

Not applicable.

\section{Competing interests}

The authors declare that they have no competing interests.

Received: 9 July 2019 Accepted: 14 November 2019

Published online: 11 December 2019

\section{References}

1. Akhtar MI, Hamid M, Minai F, Wali AR, Anwar UI H, Aman-Ullah M, Ahsan K. Safety profile of fast-track extubation in pediatric congenital heart disease surgery patients in a tertiary care hospital of a developing country: an observational prospective study. J Anaesthesiol Clin Pharmacol. 2014;30(3): 355-9.

2. van Mastrigt GA, Maessen JG, Heijmans J, Severens JL, Prins MH. Does fasttrack treatment lead to a decrease of intensive care unit and hospital length of stay in coronary artery bypass patients? A meta-regression of randomized clinical trials. Crit Care Med. 2006;34(6):1624-34.

3. Zhu F, Lee A, Chee YE. Fast-track cardiac care for adult cardiac surgical patients. Cochrane Database Syst Rev. 2012;10:CD003587.

4. Svircevic V, Nierich AP, Moons KG, Brandon Bravo Bruinsma GJ, Kalkman CJ, van Dijk D. Fast-track anesthesia and cardiac surgery: a retrospective cohort study of 7989 patients. Anesth Analg. 2009;108(3):727-33.

5. Cheng DC, Wall C, Djaiani G, Peragallo RA, Carroll J, Li C, Naylor D. Randomized assessment of resource use in fast-track cardiac surgery 1-year after hospital discharge. Anesthesiology. 2003;98(3):651-7.

6. Djaiani GN, Ali M, Heinrich L, Bruce J, Carroll J, Karski J, Cusimano RJ, Cheng DC. Ultra-fast-track anesthetic technique facilitates operating room extubation in patients undergoing off-pump coronary revascularization surgery. J Cardiothorac Vasc Anesth. 2001;15(2):152-7.

7. Zayat R, Menon AK, Goetzenich A, Schaelte G, Autschbach R, Stoppe C, Simon TP, Tewarie L, Moza A. Benefits of ultra-fast-track anesthesia in left ventricular assist device implantation: a retrospective, propensity score matched cohort study of a four-year single center experience. J Cardiothorac Surg. 2017;12(1):10.

8. Kianfar AA, Ahmadi ZH, Mirhossein SM, Jamaati H, Kashani BS, Mohajerani SA, Firoozi E, Salehi F, Radmand G, Hashemian SM. Ultra fast-track extubation in heart transplant surgery patients. Int J Crit IIIn Inj Sci. 2015; 5(2):89-92.

9. Meissner U, Scharf J, Dotsch J, Schroth M. Very early extubation after openheart surgery in children does not influence cardiac function. Pediatr Cardiol. 2008;29(2):317-20.

10. Andropoulos DB, Hunter JV, Nelson DP, Stayer SA, Stark AR, McKenzie ED, Heinle JS, Graves DE, Fraser CD Jr. Brain immaturity is associated with brain injury before and after neonatal cardiac surgery with high-flow bypass and cerebral oxygenation monitoring. J Thorac Cardiovasc Surg. 2010;139(3): 543-56.

11. Miller SP, McQuillen PS, Hamrick S, Xu D, Glidden DV, Charlton N, Karl T, Azakie A, Ferriero DM, Barkovich AJ, et al. Abnormal brain development in newborns with congenital heart disease. N Engl J Med. 2007;357(19):1928-38.

12. Miatton $M$, De Wolf $D$, Francois $K$, Thiery $E$, Vingerhoets $G$. Neuropsychological performance in school-aged children with surgically corrected congenital heart disease. J Pediatr. 2007;151(1):73-8 78 e71.

13. Larsen SH, Emmertsen K, Johnsen SP, Pedersen J, Hjortholm K, Hjortdal VE. Survival and morbidity following congenital heart surgery in a populationbased cohort of children--up to 12 years of follow-up. Congenit Heart Dis. 2011;6(4):322-9.

14. Char D, Ramamoorthy C, Wise-Faberowski L. Cognitive dysfunction in children with heart disease: the role of anesthesia and sedation. Congenit Heart Dis. 2016;11(3):221-9.

15. Borracci RA, Ochoa G, Ingino CA, Lebus JM, Grimaldi SV, Gambetta MX. Routine operation theatre extubation after cardiac surgery in the elderly. Interact Cardiovasc Thorac Surg. 2016;22(5):627-32.

16. Berghmans JM, Poley MJ, van der Ende J, Weber F, Van de Velde M, Adriaenssens P, Himpe D, Verhulst FC, Utens E. A visual analog scale to assess anxiety in children during anesthesia induction (VAS-I): results supporting its validity in a sample of day care surgery patients. Paediatr Anaesth. 2017;27(9):955-61.

17. Riker RR, Fraser GL, Cox PM. Continuous infusion of haloperidol controls agitation in critically ill patients. Crit Care Med. 1994;22(3):433-40.

18. Alghamdi AA, Singh SK, Hamilton BC, Yadava M, Holtby H, Van Arsdell GS, Al-Radi OO. Early extubation after pediatric cardiac surgery: systematic review, meta-analysis, and evidence-based recommendations. J Card Surg. 2010;25(5):586-95.

19. Fischer JE, Allen P, Fanconi S. Delay of extubation in neonates and children after cardiac surgery: impact of ventilator-associated pneumonia. Intensive Care Med. 2000;26(7):942-9.

20. Reddy SL, Grayson AD, Griffiths EM, Pullan DM, Rashid A. Logistic risk model for prolonged ventilation after adult cardiac surgery. Ann Thorac Surg. 2007; 84(2):528-36.

21. Badhwar V, Esper S, Brooks M, Mulukutla S, Hardison R, Mallios D, Chu D, Wei L, Subramaniam K. Extubating in the operating room after adult cardiac surgery safely improves outcomes and lowers costs. J Thorac Cardiovasc Surg. 2014;148(6):3101-9 e3101

22. Garg R, Rao S, John C, Reddy C, Hegde R, Murthy K, Prakash PV. Extubation in the operating room after cardiac surgery in children: a prospective observational study with multidisciplinary coordinated approach. J Cardiothorac Vasc Anesth. 2014;28(3):479-87.

23. Bainbridge D, Cheng DC. Early extubation and fast-track management of off-pump cardiac patients in the intensive care unit. Semin Cardiothorac Vasc Anesth. 2015;19(2):163-8.

\section{Publisher's Note}

Springer Nature remains neutral with regard to jurisdictional claims in published maps and institutional affiliations. 